\title{
Assentamentos rurais e relações de interdependência: ambiguidades no reconhecimento dos assentados na região estancieira do Rio Grande do Sul
}

\author{
Rural settlements and interdependence relations: ambiguities in the recognizing \\ of assentados in estancieira region of Rio Grande do Sul
}

Asentamientos rurales y relaciones de interdependencia: ambigüedades en el reconocimiento de los assentados en la región estanciera de Rio Grande do Sul

\author{
Francis Casagranda Zanella ${ }^{1}$ \\ Marcos Botton Piccin²
}

Recebido em 19/02/2018; revisado e aprovado em 03/06/2018; aceito em 06/06/2018 DOI: http://dx.doi.org/10.20435/inter.v20i4.1847

\begin{abstract}
Resumo: O objetivo deste artigo é entender como os assentados e os sem-terra são representados pelos antigos moradores de um município da região estancieira do Rio Grande do Sul. A partir de uma abordagem etnográfica, atenta-se para a sociodinâmica da estigmatização. Com os resultados, verificou-se a transição de um primeiro momento, no qual se estabeleceu uma vinculação tensa e de oposição à política de assentamentos rurais, para um segundo, em que os antigos moradores alcançam uma posição mais amena e ambígua de relação e de qualificação das populações assentadas.
\end{abstract}

Palavras-chave: reforma agrária; sem-terra; estigma; conflito; poder.

\begin{abstract}
The objective of this article is to understand how the assentados and sem-terra are represented by the former residents of a municipality in Rio Grande do Sul state. Based on an ethnographic approach, we seek to understand the sociodynamics of stigmatization. With the results we identify a transition between two periods: from a tense and opposite connection with the policy of rural settlements, the former residents reach a more amicable and ambiguous position of relation and qualification of the assentados populations.

Keywords: land reform; sem-terra; stigma; conflict; power.

Resumen: El objetivo de este artículo es entender cómo los asentados y los sem-terra son representados por los antiguos habitantes de un municipio en la región estanciera de Rio Grande do Sul. A partir de un enfoque etnográfico, se busca comprender la sociodinámica de la estigmatización. Con los resultados, se observa una transición desde un primer momento en que se estableció una vinculación tensa y de oposición a la política de asentamientos rurales, a un segundo en que los antiguos habitantes alcanzan una posición más amena y ambigua de relación y de calificación de las poblaciones asentadas.
\end{abstract}

Palabras clave: reforma agraria; sem-terra; estigma; conflicto; poder.

\section{INTRODUÇÃO}

Este artigo tem como tema a inserção de populações beneficiárias da política de assentamentos rurais em espaços sociais caracterizados pela grande propriedade fundiária, tendo em conta que em alguma medida estes foram reconfigurados pelos processos de assentamento rural. Esta abordagem se faz significativa nos estudos sobre assentamentos rurais brasileiros na medida em que permite trazer novas dimensões perante o recorrente enfoque restrito às relações internas ao espaço demarcado entre seus beneficiários, organizações e o Estado. Pouco a pouco, as relações e os efeitos externos que os assentamentos provocam têm ganhado maior atenção.

Exemplos dessa perspectiva são os estudos de Medeiros e Leite (2004) e Leite et al. (2004), que deram notoriedade aos efeitos econômicos e políticos dos assentamentos rurais em escalas local e regional. Nessa tradição de análise, há uma ênfase sobre as transformações nas estruturas

\footnotetext{
${ }^{1}$ Universidade Federal Rural do Rio de Janeiro (UFRRJ), Rio de Janeiro, Rio de Janeiro, Brasil.

${ }^{2}$ Universidade Federal de Santa Maria (UFSM), Santa Maria, Rio Grande do Sul, Brasil
} 
sociais e produtivas regionais que foram provocadas pelos beneficiários dos assentamentos, ou seja, uma tentativa de se observarem efeitos sobre a estrutura agrária do país (SPAROVEK, 2003; FERRANTE; WHITAKER, 2008) . $^{3}$

A região que chamamos de estancieira é também conhecida como Campanha ou Fronteira Oeste do Rio Grande do Sul (RS). Vivenciou a partir dos anos 1980 um afrouxamento relativo nas condições de reprodução do patronato rural estancieiro enquanto principal detentor dos domínios fundiários, devido à crise econômica ocasionada pela diminuição do valor recebido pelos produtores nas vendas do gado (PICCIN, 2012).

Esse fato esteve diretamente relacionado à emergência de pressões por reforma agrária e à consolidação de assentamentos rurais na região, constituídos por famílias migrantes de diferentes porções do Rio Grande do Sul. Os estudos sobre esses novos espaços sociais e geográficos na Campanha rio-grandense apontam para emergentes propostas econômicas e políticas ali promovidas (ALVES, 2006; CHELOTTI, 2009; 2010; AGUIAR, 2011; SANTOS, 2012). Contudo pouco adentram nos modos como tais mudanças ganham notoriedade, bem como se aquelas novidades abrem ou restringem formas de ascensão e/ou afirmação social dos agentes implicados ${ }^{4}$.

Portanto o que se procura trazer em evidência neste artigo, considerando lacunas da literatura sucintamente apontada, é a carência de olhares sobre as estruturas de percepção acerca das categorias de designação "assentados" e "sem-terra", em especial desde as formas de apreciação daqueles que vivem do lado de fora dos assentamentos. Considera-se que essa compreensão depende de um olhar atento às interdependências (ELIAS, 1980), ou seja, às relações recíprocas entre grupos sociais, que dão significado para um conjunto de comportamentos e posições ocupadas por diferentes indivíduos, assim como para suas formas de compreender os espaços em que se inserem.

Em outras palavras, o estudo de uma determinada configuração social depende de um olhar sobre o conjunto dos grupos que exercem relações de poder entre si, pois as práticas só têm sentido em função da existência dos diferenciais de poder entre eles (ELIAS; SCOTSON, 2000). Sob tal perspectiva, objetiva-se analisar as significações e os graus de legitimidade atribuídos às famílias assentadas, bem como se os assentados, em sua diversidade, podem alterar os modos sob os quais são subjetivados pelos antigos moradores.

Este estudo teve como principal local do trabalho de campo o município de Santa Margarida do Sul, Estado do Rio Grande do Sul, que pode ser caracterizado como um município pequeno, extenso e rural/agrícola. Seu contingente populacional é de pouco mais de dois mil habitantes, concentrados em localidades classificadas como zona rural, em sua maioria. Sua extensão em área é de 955 km² e segue os padrões territoriais ampliados dos municípios da região estancieira, em comparação com os das regiões ocupadas pelas chamadas colônias no mesmo Estado.

Em 2008, teve início a implementação do primeiro assentamento rural nesse local, em uma área contígua à sede municipal, onde se estabeleceram aproximadamente 80 famílias. Antes disso, durante toda a década de 2000, procedeu-se um cenário polarizado de disputas no campo de conflitos agrários (DA ROS, 2006) no Rio Grande do Sul, com foco na região estancieira e centralidade de tensões em municípios como Alegrete e São Gabriel.

\footnotetext{
${ }^{3}$ Há vários outros estudos que seguem a mesma perspectiva teórico-metodológica. Porém não convém citar todos eles aqui, na medida em que seguem a esteira das conclusões dos principais autores mencionados.

${ }^{4}$ Fazem-se devidas ressalvas para estudos como o de Rosa (2000), no qual se objetivou entender a inserção de beneficiários de assentamentos rurais nas redes locais de poder em um pequeno município no RS.
} 
Nesses processos, houve um envolvimento direto de Santa Margarida do Sul, município vizinho a São Gabriel, por diversos motivos: a) as pressões dos sem-terra não enfocavam apenas São Gabriel, mas a região; b) Santa Margarida do Sul foi lugar de estratégias de mobilização tanto dos sem-terra como dos patronais (marchas, manifestações etc.); c) o Sindicato Rural de São Gabriel, um ator explicitamente contrário às mobilizações dos sem-terra ${ }^{5}$, congrega membros de ambos os municípios.

Considerando, ainda, a relação de estreita proximidade no espaço físico em torno da sede municipal entre os recém-chegados assentados e os antigos moradores, aí existe um grande campo de pesquisa para se observar mecanismos de demarcação social. Mesmo que ambos os grupos porventura quisessem manter um afastamento, o contato praticamente visual entre eles, enquanto vizinhos, pode gerar as mais diversas situações para o acionamento de mecanismos simbólicos de classificação da realidade.

Nesse contexto, neste trabalho se analisam os sentidos atribuídos pelos antigos moradores no município - os que aqui serão designados como munícipes - em relação aos novos entrantes assentados. O trabalho de campo foi constituído pela observação etnográfica (BEAUD; WEBER, 2007) na condução de 42 entrevistas, sendo 21 com assentados e 21 com munícipes, em quatro expedições realizadas durante 2016. Outras situações de observação incluem festividades, conversas informais, uma feira de produtoras assentadas e a estadia no município por aproximadamente dois meses em tempo acumulado das expedições.

Para elaborar este artigo, foram selecionados trechos de treze entrevistas que deram destaque para as relações assentados-munícipes. Dez delas foram realizadas com munícipes, tendo em vista que eles ocupavam posições como as de agente do serviço público (prefeitura e escolas), comerciante e presidente de associação. As demais foram feitas com dois assentados e uma assentada e permitiram acumular elementos para reflexão do conjunto de significações e tensões em jogo, considerando que eles demonstraram uma variabilidade de formas de retaliação aos estigmas produzidos pelos antigos moradores e, ao mesmo tempo, de resignação perante os diferenciais de poder que estruturam a configuração social.

O presente texto está subdividido em outras três seções. Procura-se, em primeiro momento, compreender como se forjaram as interdependências entre antigos e novos moradores conforme se deu o ingresso dos sem-terra enquanto novos agentes no âmbito local, uma relação notadamente demarcada pela oposição entre os grupos. Em segundo momento, a intenção foi perceber em que medida se operou uma diferenciação dos assentados perante os antigos moradores das redondezas quando vistos à luz da posse de certas lógicas de conduta expressas, principalmente, em seus lotes de terra. Por fim, apontam-se algumas considerações sobre o estudo das relações de interdependência no contexto de assentamentos rurais.

Cabe ainda destacar que ao longo do texto utilizaremos as aspas simples (") para designar as palavras ou as falas dos pesquisados que foram registradas em entrevistas ou anotadas em caderno de campo. A palavra 'assentados', com aspas simples, designará os diferentes sentidos atribuídos pelos pesquisados; já o seu uso sem aspas significará apenas que são populações beneficiárias de uma política pública de assentamentos rurais.

\footnotetext{
${ }^{5}$ Como se pode notar em matérias publicadas em jornais: Prefeito e produtores reagem ao decreto (Zero Hora, 21/05/2003); Ruralistas tentam evitar a desapropriação (Correio do Povo, 22/05/2003).
} 


\section{AS OPOSIÇÕES ENTRE NOVOS E ANTIGOS MORADORES}

Entre 2001 e até depois de 2008, sucederam-se inúmeros acontecimentos no âmbito dos conflitos agrários no Rio Grande do Sul que ganharam destaque nos principais jornais do Estado ${ }^{6}$, evidenciando as tensões geradas na região estancieira em torno das pautas dos sem-terra e dos autointitulados produtores rurais ${ }^{7}$. Um dos principais focos de atenção das notícias na região foi o município de São Gabriel, vizinho de Santa Margarida do Sul, que se tornou lugar estratégico para as lutas simbólicas dos proprietários e dos sem-terra, na medida em que estes últimos reivindicavam desapropriações de terras para "colocar uma estaca no coração do latifúndio" e que os primeiros procuravam afirmar hegemonia em frases como "esta terra tem dono" (GÖRGEN, 2004).

Tanto os sem-terra como os produtores rurais, durante esse período, utilizaram os mais variados repertórios de ação no intuito de dar os rumos que consideravam os mais adequados para a política agrária no Rio Grande do Sul. Os sem-terra eram geralmente vistos como pessoas 'de fora', que apresentavam certo perigo para os antigos moradores da região da Campanha.

No ano de 2008, foram adquiridos alguns imóveis rurais para fins de reforma agrária pelo Instituto Nacional de Colonização e Reforma Agrária em São Gabriel, Santa Margarida do Sul e redondezas, onde se estabeleceram aproximadamente 700 famílias de sem-terra. Em meio a este cenário de disputa contundente em torno do regime fundiário historicamente estabelecido, mobilizador de categorias sociais antagônicas (sem-terra e produtores rurais) e amplamente documentado pelos veículos midiáticos, os demais conjuntos de antigos moradores não ficaram imunes ao processo, conforme pode-se observar em declarações de munícipes que relembram o período de chegada dos novos moradores:

Logo que vieram [os sem-terra] para Santa Margarida toda comunidade ficou apavorada: "nossa, o assentamento vai vir pra dentro de Santa Margarida!", porque é dentro do perímetro urbano. "Como é que a gente vai viver?", "agora ninguém mais vai poder sair de casa!". Porque tem aquela visão né: "ah, porque vai aumentar os roubos", tudo de ruim é neles. [...] porque a gente não sabe de onde eles vieram. Era todo mundo perplexo, assim, com a história. [...]. (Maiara ${ }^{8}$, funcionária da Prefeitura; entrevista concedida em 3 de junho de 2016).

Todo mundo se conhecia aqui. Aí vem um pessoal de fora, estranho, envergonhado pela situação que estava de lona, pobreza, sujeira e falta de condições de banho, alimentação e coisa, e se misturar com os nossos. (Michel, comerciante; entrevista concedida em 7 de junho de 2016).

No início era assim olha, que eles iriam terminar com a nossa cidade, que era o sem-terra que a gente chamava, não chamava de assentados. Até a gente [funcionários públicos]. Eu estou te falando abertamente aqui, não é "coisas", assim. A gente chamava sem-terra. (Manuela, professora; entrevista concedida em 15 de junho de 2016).

Conforme se desenrolavam os episódios ocorridos anteriormente e ao longo do processo de assentamento, são nítidos os elementos de agregação do grupo antigo, expressos em termos

\footnotetext{
${ }^{6}$ Algumas matérias publicadas: Incra suspende vistorias em duas fazendas em São Gabriel (Zero Hora, 29/11/2001); Campanha teme a retomada de vistorias (Zero Hora, 19/01/2003); MST marcha hoje para São Gabriel (Correio do Povo, 10/06/2003); Abril vermelho leva sem-terra a São Gabriel (Zero Hora, 15/04/2008).

${ }^{7}$ No RS, a categoria de identificação 'produtores rurais' foi forjada nos debates que constituíram a União Democrática Ruralista (UDR), em 1986, de modo a aglutinar em torno de uma única identidade os grupos representados. A aproximação de proprietários rurais, grandes arrendatários e parceiros agrícolas teve como efeito a unificação como classe no posicionamento contrário à reforma agrária (DA ROS, 2006; p. 143-150).

${ }^{8}$ São fictícios todos os nomes usados neste trabalho a fim de designar interlocutores do trabalho de campo.
} 
como 'nossa região', 'nossa cidade', 'toda comunidade', 'todo mundo', 'a gente', 'os nossos', o que vem a reforçar o apego à estrutura de relações em que os agentes foram socializados. O uso recorrente do pronome "nós" (ELIAS, 1980) é o principal indicativo de que certo grupo social é delimitado por similaridades socialmente reconhecidas entre si e diferençadas perante outros.

Nota-se que agentes pertencentes a subgrupos como o dos localmente chamados 'migrantes' - descendentes de imigrantes europeus não ibéricos, os quais ali ocuparam no passado uma condição de novos ingressantes - também se utilizaram do mesmo sentimento de grupo dos antigos moradores para se referir aos 'assentados'. Ao mesmo tempo, forjou-se o baixo prestígio aos 'sem-terra', em que o receio foi se construindo a partir das tensões na 'briga' destes com os 'pecuaristas' e se materializou com a ideia de 'sujeira'. Palavras como 'roubos', 'estranho', 'lona', 'pobreza' e 'sujeira' fazem menção ao entendimento de risco percebido em se 'misturar'.

O fato de os sem-terra chegarem 'para dentro' de Santa Margarida do Sul foi elemento agravante das incertezas, no sentido de que poderiam 'acabar' com a cidade, ou seja, colocar em jogo a manutenção de certo estado das posições e da distribuição dos recursos. A professora reconhece um posicionamento de contrariedade que vinha de setores como o funcionalismo público, em que a forma como se usava o termo 'sem-terra' é reconhecida como algo a deixar para o passado.

Aparentemente estava em jogo, para os antigos moradores, a possibilidade de se chegar ao fim de um estado até então conservado de relações. Isso vai ao encontro de algumas declarações de exaltação do que os munícipes entendem como qualidades positivas de Santa Margarida do Sul moradores:

Pessoal daqui é tudo gente simples, mas gente boa [risos]. Não tem violência, graças a deus. Muito bom de se viver aqui, bah. Aqui [...] ainda moramos num paraíso. (Maristela, comerciante; entrevista concedida em 7 de junho de 2016).

Mas aqui é muito bom, acho que o pessoal que vem pra cá não vai embora mais [refere-se aos assentados]. É muito desenvolvida nossa região aqui, todas microrregiões têm seu time de futebol, tem seus PTGs [Piquete de Tradições Gaúchas], seus CTG [Centro de Tradições Gaúchas], em termos de tradição. [...] E a gente gosta, tradicionalismo é lugar sadio e forte. (Miguel, presidente de associação; entrevista concedida em 4 de julho de 2016)

Temos uma saúde das melhores, regionalmente não tem igual. Uma educação fora de série [...] Já tinha saúde de primeiro mundo e queríamos educação também. (Maurício, produtor rural, membro do Poder Público Municipal; entrevista concedida em 2 de junho de 2016).

Aqui se denotam algumas características exaltadas em que os agentes consideram ter em comum as trajetórias no espaço estancieiro, gostos pela tradição institucionalizada, satisfação com serviços públicos, desejos para o futuro de seus filhos, enfim, um conjunto de elementos conhecidos e qualificados como válidos entre semelhantes.

Mesmo que essas frases tenham sido proferidas em relação a um período mais recente, expressam como os antigos moradores se sentem dotados de disposições sociais legitimadas para ocupar aquele espaço e como não têm maiores preocupações com a estabilidade das condições de reprodução de seus sucessores. Nesse sentido, Elias e Scotson (2000) discutem que as afirmações do ideal de nós e da coesão grupal do establishment se baseiam na generalização do que entendem por melhores características, enquanto a desqualificação do grupo estranho ou outsider parte da generalização das piores características. 
O modo como os sem-terra vivenciam a 'luta'9 através de ocupações e de acampamentos parece ter impregnado negativamente sua imagem sob o ponto de vista dos munícipes. Processo similar foi identificado por Moura (2010) no sul do Estado do Espírito Santo, em que os moradores da cidade associaram a imagem dos acampamentos de lona dos sem-terra dispostos nas margens de rodovias com os estigmas de "baderneiros" e "invasores", convertidos em símbolos de aversão e desconfiança contra os assentados.

Tanto nesse caso citado como em Santa Margarida do Sul, a ideia de que os 'assentados' são formados por 'estranhos' e que 'não se sabe de onde vieram' é fator levantado para justificar uma distinção. Nesse sentido, conforma-se um estereótipo sobre a aparência visual dos sem-terra, ou seja, há uma imagem associada às 'lonas' e a uma condição de restrições econômicas, lembrada pela noção de 'sujeira'.

A chegada dos sem-terra e o seu posicionamento como assentados no espaço físico, relativamente próximos da sede municipal, gerou a convivência direta com as imagens das 'lonas' e sua carga de estigmas. As primeiras moradias de lona dos 'assentados' acarretam o entendimento de um "risco de contaminação" (ELIAS; SCOTSON, 2000) da relação comunitária positivada pelos munícipes como lugar onde 'todo mundo se conhecia'. O estereótipo de 'sem-terra' é construído a partir de uma vinculação tensa, forjada nas disputas do campo dos conflitos agrários (DA ROS, 2006), e tende a impor estigmas sobre todo o conjunto dos identificados pela categoria.

Na medida em que se mostravam tensas as relações entre sem-terra e produtores rurais no período entre 2001 e 2008 na região estancieira, duas tendências anexas foram estruturantes para a construção de imagens dos sem-terra em mentes munícipes. Por um lado, recorreu-se à explicitação da identificação como antigos moradores, em uma crescente afirmação como grupo coeso. Reforça-se a noção de 'nós', ou seja, a unidade como antigos moradores que supera eventuais discordâncias internas quando se trata de se diferenciar dos sem-terra.

Por outro lado, e, adicionalmente, o processo de aglutinação como grupo coeso repercutiu na construção de estigmas que marcam os novos ocupantes de posições no espaço social. Delimitaram-se marcas distintivas de baixo prestígio social aos 'assentados' de modo a afirmar as próprias características positivadas. Com isso, evidenciou-se neste espaço social o processo de diferenciação entre established/outsiders tal como analisam Elias e Scotson (2000).

Para Elias e Scotson (2000, p. 24), o discurso que parte dos estabelecidos como grupo mais poderoso tende a penetrar na autoimagem dos outsiders e enfraquecer sua capacidade de reação. Quando é grande o desequilíbrio de poder entre os grupos, os outsiders possivelmente "vivenciam sua inferioridade de poder como um sinal de sua inferioridade humana." (p. 28, grifos no original). Ou seja, seu grau de retaliação é relativamente restrito diante do grau de afirmação e estigmatização do grupo estabelecido.

Em certa medida, a situação aqui analisada difere-se do caso-gabarito de Winston Parva (ELIAS; SCOTSON, 2000), em que os novos moradores não possuíam meios para obter coesão. As afinidades grupais dos sem-terra baseadas em diversos graus de identificação com a 'luta' geraram situações de contraestigmatização explícita. Nisso, a noção de 'sem-terra' pode ser ativada de modo a reivindicar reconhecimento. Seu uso situa-se entre a resignação pelo estigma

\footnotetext{
${ }^{9}$ Comerford (1999) analisa como a categoria "luta" pode ser alvo de diversos significados conforme o universo social dos agentes e as formas de acioná-la para dar sentido às suas vivências. No decorrer deste trabalho, a noção de 'luta' geralmente corresponde aos processos de mobilização dos quais as famílias sem-terra fizeram parte antes de se converterem em assentadas.
} 
e a afirmação pela 'luta', considerando que emerge de um processo de socialização grupal mais curto perante o do establishment.

Algumas menções sobre retaliação e resignação por parte dos sem-terra foram ouvidas ao longo de entrevistas com eles realizadas. No relato de César, um assentado que já ocupou posições de liderança no interior da estrutura organizativa dos acampamentos do Movimento dos Trabalhadores Rurais Sem Terra (MST) e que, atualmente, não atua mais diretamente na 'militância', mantém-se uma identificação com a categoria 'sem-terra' mesmo que a condição oficial seja de assentado:

O pessoal [munícipe] estava nos refugando nos primeiros dias. No ônibus eu escutava os caras fofocando, falando mal de nós. Daí um dia eu sentei do lado de uma mulher, até que ela me perguntou: "você é ali que está morando na fazenda do finado [estancieiro]?". Nem chamou de assentamento. Eu disse "estou, sou assentado ali". Ela fez umas mil perguntas. Eu falei: "o nosso pessoal são tudo gente como vocês". Digo: "só somos sem-terra porque somos sem-terra mesmo, não tinha terra, e não temos. Nós temos uma concessão de uso do Incra". [...] Eles [munícipes] acham que a vida do sem-terra é outra, eles acham que o cara é como um bicho. Eles olham na TV o sem-terra ocupando fazenda e sai muita coisa distorcida, que o cara é baderneiro. Mas isso [baderneiro] tem em toda parte! (César, assentado; entrevista concedida em 21 de junho de 2016).

Em oposição à classificação negativa de categorias como 'sujeira' e 'baderna', é notável que a condição de 'sem-terra' não só é correlata às privações materiais dos acampados, mas é positivada no âmbito das mobilizações, de modo a constituir elemento afirmativo da 'luta' pela terra. As privações materiais não são vivenciadas unicamente como sinais de vergonha, mas se tornam símbolos de afirmação, de ser 'gente como vocês'. Características tomadas como positivas no grupo são reforçadas enquanto se relativizam aquelas que podem ser tomadas como negativas: 'baderneiro tem em toda parte'.

Nesse sentido, torna-se efetiva a diferença de disposições sociais entre assentados e munícipes, em que uma condição objetiva de privação material é reconhecida como estigma, por um lado, e sinal de orgulho, por outro; é generalizada por um lado e relativizada pelo outro. Em outras palavras, as regras de jogo não são totalmente equivalentes entre os espaços sociais. Atribui-se valor diferente às categorias de pensamento internalizadas de acordo com os processos de socialização.

Portanto essa primeira citação retrata uma situação de afirmação das condições objetivas dos sem-terra. Nela, trata-se de retaliar a generalização daquelas que são consideradas as piores características do grupo pelo establishment. Porém, em outros casos, recorre-se a um posicionamento resignado. A assentada Renata, também ex-ocupante de posições de liderança no âmbito da 'militância' no MST, relata uma situação que presenciou:

Vi muitas mães daqui de dentro [assentamento] que não foram dar a cara à tapa. Elas [algumas professoras] humilhavam [filhos de assentados], mas depois chamavam [suas mães]: "ah, vamos ali na secretaria, vou te dar um casaquinho". Aí [as mães] não transferiam [os filhos] da escola. O filho está sendo humilhado, mas tu ganha um casaco, uma calça, entendeu? Tipo pra manter quieta [...]. (Renata, assentada; entrevista concedida em 28 de junho de 2016).

O relato de inconformidade dessa mãe assentada em reação a uma situação que considera inaceitável e recorrente na relação professor-aluno da escola demonstra o balanço entre resignação e retaliação. 'Dar a cara à tapa' exige uma situação de enfrentamento, enquanto 'se 
manter quieta' pode gerar o acesso restringido a certas benesses. Os diferenciais de poder e de acesso a recursos pesam negativamente aos assentados nesse tipo de situação, o que também foi percebido por Ferrante (2003) na reprodução de uma "cultura da dádiva" entre Poder Público local e algumas famílias durante a estruturação de assentamentos de Araraquara, em São Paulo.

Rosa (2000) analisou situação similar em assentamento próximo de Porto Alegre no Rio Grande do Sul. O autor identificou grupos established/outsider de assentados, separados pelo acesso concentrado a recursos e relações raros. A parcela outsider obteve redes alternativas, em que relações clientelistas com algumas lideranças políticas munícipes permitiram a construção de um canal restringido de acesso a recursos de poder locais. Ou seja, aceitar privações pode ser entendido como escolha de menor custo quando considerados os bloqueios de uma posição desprivilegiada.

Visualiza-se que o grau relativamente fraco de coesão entre os 'assentados' promove a ocorrência de situações diversas em relação à afirmação como grupo. Se por um lado é recorrente a positivação de uma identidade 'sem-terra', por outro existem certas parcelas de assentados que se sentem resignados pelos estigmas. A resignação ou a afirmação podem ser sentidas diferentemente a partir de contextos ou situações específicas de convivência entre assentados e munícipes, conforme a estrutura desigual de poder da configuração social gere maior ou menor grau de constrangimento diante das estruturas internas de apreciação e ação dos indivíduos estigmatizados.

Comparativamente, uma retaliação durante viagem de ônibus, como relatado na entrevista de César, pode ser relativamente menos arriscada do que retaliar uma professora no ambiente da escola. Os recursos em jogo são diferentes e podem levar a comportamentos distintos: no caso do ônibus, tem-se a perder a reputação perante um indivíduo desconhecido; no caso da escola, é possível perder momentaneamente o acesso dos filhos à educação pública. Portanto a análise da afirmação de categorias outsiders como a dos 'assentados' precisa ser, além de diferençada entre características deles próprios, diferenciada de acordo com uma dimensão contextual.

\section{A EMERGÊNCIA DE NOVOS ELEMENTOS DE SIGNIFICAÇÃO}

Desde os primeiros contatos com o trabalho de campo desta pesquisa, em 2016, percebia-se certa dificuldade entre os interlocutores não beneficiários do assentamento em tornar objetivo o termo 'assentados'. Nas conversas menos formalizadas com atendentes de pequenos estabelecimentos comerciais, por exemplo, elogios eram direcionados aos novos moradores - 'são gente boa' -, sempre acompanhados de avisos: 'mas nem todos'.

Também se notou certo esforço de objetivação nas conversas e entrevistas mais sistemáticas com agentes do Poder Público que não eram assentados. Algumas frases eram repetidamente proferidas por essas figuras em tom otimista para a relação entre novos e antigos moradores: 'os assentados são munícipes, não têm diferença'. Não que afirmar isso seja uma dificuldade em si, mas o ato de reafirmá-lo recorrentemente demonstra certo trabalho de objetivação.

Com o acumular de observações, diálogos e reflexões, tanto a ambiguidade do termo 'assentados', usado simultaneamente em referência a pessoas 'boas' e 'ruins', como a contínua explicitação de inexistência de diferenças entre 'assentados' e munícipes tornaram-se chaves de leitura para analisar a estruturação da posição social de 'assentados' no espaço de relações dos antigos moradores. 
Portanto, no trabalho de campo em Santa Margarida do Sul, percebeu-se que a legitimação dos assentados pelos munícipes está envolta em ambiguidades. Partindo de um nível geral das qualificações, foi praticamente consenso que os 'assentados' estão hoje 'integrados' e em 'paz' com os antigos moradores. Por outro lado, também foi recorrente a menção de algumas características entendidas como negativas. Nem sempre tais características eram direcionadas ao conjunto de assentados, mas sempre identificavam uma parcela causadora de desconforto. Aquela generalização de características negativas para o conjunto de indivíduos de um grupo outsider, notada por Elias e Scotson, não se faz mais tão presente.

Entre os munícipes, a palavra 'assentados' é ambígua na medida em que necessita de explicações adicionais para ser corretamente expressa, com base na existência de imagens díspares acerca do grupo. Quando o pesquisador fazia perguntas que exigiam algum tipo de qualificação sobre as pessoas do assentamento, surgiam valorações distintas para a categoria. Isso pode ser percebido a partir de alguns trechos recortados de entrevistas com munícipes:

[...] quase 90\% das nossas cestas básicas são entregues no [assentamento] [...] Tem pessoas trabalhadoras que se destacam no [assentamento], tiradores de leite, pessoas que plantam, que produzem, mas também tem pessoas que precisam de atendimento, são muito carentes. (Secretária no Poder Público Municipal; entrevista concedida em 31 de maio de 2016).

Acho que eles vão começar a produzir. Quem for, quem gostar. Mesma coisa que sala de aula, quem não gosta vai fazer um trabalho do jeito que vai andar. [...] Mas ai tu olha casinhas pintadinhas: os que tiverem vontade eles vão ir para frente. Eles vão ter que começar a produzir, é o que eu acho. [...] (Professora na escola A; entrevista concedida em 15 de junho de 2016).

Esses dias eu estava comentando que eu tenho que ir no assentamento visitar, porque eu não conheço essa realidade deles, de cada um. Mas pelo que percebo, observo, é bem precário, bem pobre em todos os sentidos. [...] eu tenho que fazer esse trabalho, ver aquilo que eles estão se diferenciando dos outros [diferenças entre os filhos de assentados], alguma coisa está acontecendo lá. (Professora na escola B; entrevista concedida em 4 de julho de 2016).

[...] para nós era novidade, a gente não via uma criança chegar aqui na escola e dizer " $n a ̃ o$ comi hoje". [...] também tem crianças que o pai está preso, que também não era realidade nossa, coisas que foram chegando junto. Mas, assim, no geral, as crianças em si tu não vê diferença "ah, essa criança é mais ou menos porque está no assentamento". (Outra professora na escola A; entrevista concedida em 2 de junho de 2016).

O pessoal do assentamento é muito evangélico né, bastante evangélico. Tem também a parte católica que, se não me engano, tem pastoral da criança. É lá na sede [do assentamento]. Eles pesam [as crianças] e fazem as coisas, não sei se está ativo. Bem joia né, [...] mas são bem religiosos. (Funcionária na Prefeitura Municipal; entrevista concedida em 3 de junho de 2016).

Percebe-se, no conjunto dessas falas, a contrariedade em tratar dos assentados como grupo homogêneo. E, de fato, a diversidade dos assentamentos rurais é um elemento amplamente reconhecido na literatura especializada. Mas nota-se que o entendimento nativo sobre a categoria 'assentados' acaba se forjando com as ambiguidades.

Emergem elementos descritivos 'normais' e 'estranhos': quando se apontam características pretensamente negativas, como a demanda de 'cestas básicas', remedia-se a frase citando as 'pessoas trabalhadoras'; quando se comenta que crianças 'passam fome' e têm 'parente preso', remedia-se pela média onde 'não se vê diferença' quanto à normalidade; quando se afirma negativamente que 'são muito evangélicos', logo se contrabalanceia com a presença positivada de 
fiéis da igreja católica que conduzem uma pastoral da criança, mesmo sem garantir que ela seja operante. A professora demonstra um desconforto por não conhecer cada família antes de julgar os rendimentos escolares díspares entre alunos, mas reconhece 'alguma coisa acontecendo lá'. Outra professora aposta na prosperidade dos 'assentados', mas demonstra incertezas e distinções quando afirma que alguns 'vão produzir' porque 'gostam' ou têm 'vontade'.

Em outras palavras, a memória latente dos estigmas dos sem-terra permanece enquanto dissimulada na descrição da diversidade dos 'assentados'. 'Assentados' não são mais vistos tal como o estereótipo 'sem-terra', mas não se livram totalmente de algumas marcas que permanecem como relativas ao baixo prestígio. Ao mesmo tempo, também se imbuem de marcas positivadas.

Passado um período inicial de tensões mais acirradas, a relação entre 'assentados' e munícipes carrega ponderações que vão se expressar na linguagem. Enquanto a denominação 'sem-terra' continua carregada de elementos depreciativos, a denominação 'assentados' se coloca em patamar mais positivado. Seguem algumas declarações munícipes de modo a exemplificar os usos e desusos das denominações 'assentados' e 'sem-terra':

Toda essa parte aí dos sem-terra, dos assentados, não sei como que chamam, era do campo do Seu [estancieiro] [...]. (Margarida, antiga moradora; entrevista concedida em 28 de junho de 2016).

Mas o sem-terra hoje tem mais terra do que eu, porque eu não tenho terra. Eu moro dentro de uma propriedade que é do meu pai, que é assim que a gente fez uma casa e tudo. (Manuela, professora; entrevista concedida em 15 de junho de 2016).

Visualiza-se que as situações do uso da denominação 'sem-terra' podem ser permeadas por certo desconforto, vide o embaraço diante do pesquisador: 'sem-terra, assentados, não sei como que chamam'. Já a denominação 'assentados' costumava ser expressa em situações relativamente mais harmônicas de menção ao grupo. Enquanto a primeira era preferencialmente evitada em frente ao pesquisador, a segunda se mostrava como ajustada para uma relação formal.

A denominação 'sem-terra' também foi usada como um trocadilho: 'os sem-terra hoje têm mais terra do que eu!'. Nota-se que o tom de brincadeira em uma relação social não é mera casualidade. Comerford (1999, p. 81-92) toma como objeto de estudo o uso da categoria nativa "brincadeiras" (piadas, charadas etc.) enquanto forma de relação social. Objetivar o seu uso "contextual e estratégico" permite situar relações de poder, posições de enunciação e disputas simbólicas entre agentes diferentemente situados no espaço social. Nesse sentido, considera-se que permanece um nível de tensão para fazer o uso mais adequado da palavra 'sem-terra', vista sua seleção estratégica para situações propositalmente redutoras de tensões, como nas formalidades e brincadeiras.

O grau de tensão ainda existente na adequação de uso das palavras a cada situação faz com que se retome aqui o aspecto contextual das designações. Conforme Roberto, para um assentado que mantém contato diário com munícipes por meio da construção civil, a palavra 'sem-terra' pode ser usada pelo establishment local enquanto ofensa ou xingamento: "Aí primeira coisa quando querem te ofender é: 'ô sem-terra!', 'ô pobre!', ô isso e aquilo." (entrevista concedida em 29 de junho de 2016). Para ele, a denominação sem-terra teria o mesmo peso de outras denominações depreciativas direcionadas a outros grupos desprestigiados.

Portanto percebe-se que a palavra 'sem-terra' tanto pode surgir em uma situação de embaraço como pode ocupar funções estratégicas. Entre estas últimas, destaca-se a diferença entre os sentidos de formalidade e brincadeira, usados oficialmente e em entrevista com o pesquisador, diante do sentido de ofensa que é possível para uma relação direta e hostil com o ente a ser injuriado. 
Outro fator de legitimação das famílias assentadas é o quanto conseguem tornar explícita em seus lotes a instalação de um padrão 'bonito' ou demonstrativo de 'trabalho'. Os elementos materializados, visíveis para quem 'visita' o assentamento, são tomados como maiores provas da diferenciação e existência de 'assentados' legítimos e ilegítimos. As famílias que 'plantam' e 'tiram leite', que têm um lote 'ajeitado' e que construíram as 'casinhas pintadinhas' angariam um status de legitimidade como 'pessoas trabalhadoras' que 'vão produzir' e 'vão prosperar'.

Na outra parcela, estão aqueles que pouco ou nada modificaram os lotes para implementar estratégias produtivas, os que não constituíram casas sem ser as de lona ou madeira. Quando apresentam privações materiais visíveis, são representados como os que 'não trabalham', são 'carentes', 'sem vontade' ou 'que não se ajudam'. Nesse sentido, programas assistenciais ou de renda mínima, como as 'cestas básicas' ou o 'bolsa família', são percebidos como marcas de 'pobreza', ou seja, de baixo prestígio. Nisso, ganha evidência a diferenciação pelos saberes e pelos recursos econômicos que forem objetivados na organização estética e produtiva dos lotes.

Portanto, passados alguns anos desde quando o cenário era de oposição entre sem-terra e munícipes, nota-se que as relações se configuram para além da dualidade established/outsiders. Nessa perspectiva, diferenciam-se as formas de conceber a presença dos 'assentados' sob diferentes condições de vinculação. Estruturam-se no espaço social outros conjuntos de objetivações dos agentes que não os restritos à dualidade de posições entre assentados e munícipes. Nesse sentido, a partir das categorias utilizadas na fala de munícipes, explicitam-se certas características visualizadas em parcelas de 'assentados' que os alçam a status diferenciados.

Na medida em que se constituem propriedades ou capitais (BOURDIEU, 1989) classificáveis, estes são usados para definir o que é bem ou malvisto, o que é 'assentado' 'bom' ou 'ruim', ou ainda, para diferenciar 'assentados' que 'deram certo' dos que 'não deram certo'. Este pode ser um meio para compreender como a condição e a posição social de assentados podem se diferenciar e galgar possibilidades de (des)legitimação junto a diferentes frações de munícipes. Em outras palavras, tais distinções podem representar redimensionamentos na estrutura geral de distribuição dos recursos de poder na configuração social (ELIAS; SCOTSON, 2000).

\section{CONSIDERAÇÕES FINAIS}

Um dos aspectos visíveis no primeiro conjunto de declarações munícipes trazidas para o texto é que a atribuição de estigmas aos assentados articula-se discursivamente como memória, ou seja, acontecimento do passado, restrito ao 'início', que 'ainda se lembra de algumas coisas'. Nesse sentido, falar da relação atual entre 'assentados' e munícipes parece sempre evocar alguma afirmação de 'harmonia', 'paz', 'respeito' e 'integração'. Aquele alto nível de tensão inicial foi alterado após oito anos de chegada dos 'sem-terra'. Parece distante a ideia de que os 'estranhos' 'de fora' causariam o 'fim' de Santa Margarida do Sul. Qualitativamente, evidencia-se uma redução dos níveis de tensão entre os grupos que estavam em oposição.

No caso-gabarito da cidade de nome fictício Winston Parva, estudado por Elias e Scotson (2000), a chegada dos "de fora" a partir de um loteamento anexo a um antigo bairro de trabalhadores ingleses foi tão rápida quanto a instalação do assentamento nas adjacências da sede municipal e de pequenas localidades de Santa Margarida do Sul. Naquele contexto, os estigmas foram construídos conforme elementos progressivamente pinçados das "piores" características dos outsiders a partir das situações de convivência encontradas nos crescentes contatos entre os grupos. 
Já no caso dos assentamentos rurais na região estancieira do Rio Grande do Sul há um processo prévio de acúmulo de tensões e formação de estereótipo negativo, determinado pelos conflitos nas disputas pela política agrária que antecedem a implantação de assentamentos. Essa carga de preconceitos conduz ao erguimento de fortes barreiras diante do ingresso dos 'sem-terra', mesmo antes dos primeiros contatos entre novos e antigos moradores de uma localidade receptora de assentamentos rurais. Em outras palavras, a configuração de poderes no espaço social estabelece condições prévias de assimilação dos novos agentes na estrutura social. Tal condição pode se traduzir em restrições aos sem-terra quando são os grandes proprietários de determinada região que possuem uma posição dotada de maior prestígio.

Enquanto em Winston Parva a distinção entre grupos decorreu do acúmulo de estigmas, principalmente após a chegada dos 'de fora', percebeu-se em Santa Margarida do Sul uma redução relativa de tensões desde a chegada dos 'estranhos' até se atingir um novo patamar, ainda distintivo. Em outras palavras, o posicionamento dos 'assentados' no espaço social passou por uma reconfiguração relativa desde seu ingresso.

Por um lado, a posição outsider perante a estrutura de posições sociais dos munícipes é uma condição tanto de 'sem-terra' como de 'assentados' em função das condições de formação dos grupos. Mas, por outro lado, existem disposições sociais acumuladas pelos 'assentados' em processos de socialização diferentes que vão lhes permitir assumir posições com maior grau de legitimidade no conjunto do município. Entre essas, destacam-se as condições para organizar produtivamente um lote de terras.

Ressalta-se que a ocupação de espaços físicos próximos não se constitui em uma integração automática de espaços sociais e de assimilação das formas de ação e de apreciação da ação. Tal proximidade não pode ser naturalmente assimilada como tendência linear de redução das diferenças ou 'dessegregação' (BOURDIEU, 2013). Conclui-se no mesmo sentido de Rosa (2000, p. 208): as "situações sociais" originadas no embate entre beneficiários da política de assentamentos rurais e "comunidades políticas anteriormente estruturadas" passam por uma tendência de redimensionamento das "percepções de direitos e conseqüentemente de pertencimento" para ambos os grupos implicados.

Entende-se que a lenta mudança no patamar das tensões entre um período de 'sem-terra' e munícipes para um de 'assentados' e munícipes se torna importante objeto de reflexão em estudos sobre assentamentos rurais, a fim de entender como se constroem significações entre os grupos e como se dão ou não redimensionamentos dos diferenciais de poder dentro de uma escala mais ampla que a do assentamento em si. Compreender em que medida as relações entre esses grupos interferem na reprodução objetiva das condições produtivas dos lotes das famílias assentadas é uma questão em potencial para futuras pesquisas em assentamentos rurais.

\section{REFERÊNCIAS}

AGUIAR, Julia Saldanha Vieira de. Uso da terra, técnica e territorialidade: os assentamentos de Santana do Livramento/RS. 2011. 225 f. Dissertação (Mestrado em Geografia) - Universidade Federal do Rio Grande do Sul, Porto Alegre, 2011.

ALVES, Flamarion Dutra. Os impactos da territorialização dos assentamentos rurais em Candiota-RS. 2006. 137 f. Dissertação (Mestrado em Extensão Rural) - Universidade Federal de Santa Maria, Santa Maria, RS, 2006. 
BEAUD, Stéphane; WEBER, Florence. Observar. In: BEAUD, S.; WEBER, F. Guia para a pesquisa de campo: produzir e analisar dados de campo. Petrópolis, RJ: Vozes, 2007. p. 95-117.

BOURDIEU, Pierre. Espaço físico, espaço social e espaço físico apropriado. Estudos Avançados, São Paulo, v. 27, n. 79, p. 133-144, 2013.

BOURDIEU, Pierre. O poder simbólico. Rio de Janeiro: Bertrand Brasil, 1989.

CHELOTTI, Marcelo Cervo. A estância metamorfoseou-se: (re) configurações territoriais e expressões da reterritorialização camponesa na Campanha Gaúcha (1990-2007). 2009. 288 f. Tese (Doutorado em Geografia) - Universidade Federal de Uberlândia, Uberlândia, MG, 2009.

CHELOTTI, Marcelo Cervo. Novos territórios da reforma agrária na campanha gaúcha. Cam-po-Território, Uberlândia, MG, v. 5, n. 10, p. 194-225, ago. 2010.

COMERFORD, John Cunha. Fazendo a luta: sociabilidade, falas e rituais na construção de organizações camponesas. Rio de Janeiro: Relume Dumará, 1999.

DA ROS, César Augusto. As políticas agrárias durante o governo Olívio Dutra e os embates sociais em torno da questão agrária gaúcha (1999-2002). 2006. 477 f. Tese (Doutorado de Ciências Sociais em Desenvolvimento, Agricultura e Sociedade) - Universidade Federal Rural do Rio de Janeiro, Rio de Janeiro, 2006.

ELIAS, Norbert. Introdução à sociologia. Braga, Portugal: Pax/Edições 70, 1980.

ELIAS, Norbert; SCOTSON, John. L. Os estabelecidos e os outsiders: sociologia das relações de poder a partir de uma pequena comunidade. Tradução de Vera Ribeiro. Rio de Janeiro: Jorge Zahar Editor, 2000.

FERRANTE, Vera Lúcia Silveira Botta. Assentamentos rurais: entre a cultura da dádiva e novas perspectivas de participação. In: CONGRESSO BRASILEIRO DE SOCIOLOGIA, 11., 2003, Campinas, SP. Anais [...]. Disponível em: http://www.sbsociologia.com.br/portal/index.php?option=com_docman\&task=cat_ view\&gid=106\&ltemid=171. Acesso em: 8 jun. 2017.

FERRANTE, Vera Lúcia Silveira Botta; WHITAKER, Dulce Consuelo Andreatta (Org.). Reforma agrária e desenvo/vimento: desafios e rumos da política de assentamentos rurais. Brasília: MDA; São Paulo: Uniara, 2008.

GORGEN, Sérgio Antônio. Marcha ao coração do latifúndio. Petrópolis, RJ: Vozes, 2004.

IBGE. Instituto Brasileiro de Geografia e Estatística. Cidades. Rio Grande do Sul. Santa Margarida do Sul. Disponível em: https://cidades.ibge.gov.br/brasil/rs/santa-margarida-do-sul/panorama. Acesso em: 13 fev. 2017.

LEITE, Sérgio Pereira; HEREDIA, Beatriz A. de; MEDEIROS, Leonilde S. de; PALMEIRA, Moacir; CINTRÃO, Rosangela. Impactos dos assentamentos: um estudo sobre o meio rural brasileiro. São Paulo: Editora UNESP; Brasília: NEAD, 2004. (Estudos NEAD, n. 6).

MEDEIROS, Leonilde Servolo de; LEITE, Sérgio (Org.). Assentamentos rurais: mudança social e dinâmica regional. Rio de Janeiro: Mauad, 2004.

MOURA, Roseni Aparecida de. "Imagem de nós": relações de estabelecidos e outsiders entre população urbana e assentados de reforma agrária do sul do Espírito Santo. 2010. 103 f. Dis-sertação (Mestrado em Extensão Rural) - Universidade Federal de Viçosa, Viçosa, MG, 2010. 
PICCIN, Marcos Botton. Os senhores da terra e da guerra do Rio Grande do Sul: um estudo sobre as estratégias de reprodução social do patronato rural estancieiro. 2012. 457 f. Tese (Doutorado em Ciências Sociais) - Universidade Estadual de Campinas, Campinas, SP, 2012.

ROSA, Marcelo Carvalho. Assentados e munícipes: o conflito entre beneficiários e população local na reforma agrária brasileira. Revista Crítica de Ciências Sociais, Coimbra, Portugal, n. 57/58, p. 207-29, jun./nov. 2000.

SANTOS, Anderson Luiz Machado dos. O emergir de um novo território camponês: conquistas e transformações do latifúndio - o caso de São Gabriel - RS. 2012. 200 f. Dissertação (Mestrado em Geografia) - Universidade Federal de Santa Maria, Santa Maria, RS, 2012.

SPAROVEK, Gerd. A qualidade dos assentamentos da reforma agrária brasileira. São Paulo: Páginas \& Letras, 2003.

\section{Sobre os autores:}

Francis Casagranda Zanella: Doutorando em Ciências Sociais em Desenvolvimento, Agricultura e Sociedade pela Universidade Federal Rural do Rio de Janeiro (CPDA/UFRRJ). Mestre em Extensão Rural pela Universidade Federal de Santa Maria (PPGExR/UFSM). Graduado em Gestão Ambiental pela Universidade Federal do Pampa (Unipampa). E-mail: franciszanella@gmail.com, Orcid: http://orcid.org/0000-0002-2354-5201

Marcos Botton Piccin: Doutor em Ciências Sociais pela Universidade Estadual de Campinas (Unicamp). Mestre em Ciências Sociais em Desenvolvimento, Agricultura e Sociedade pela Universidade Federal Rural do Rio de Janeiro (CPDA/UFRRJ). Graduado em Medicina Veterinária pela Universidade Federal de Santa Maria (UFSM). Professor adjunto da Universidade Federal de Santa Maria (UFSM), Departamento de Educação Agrícola e Extensão Rural. E-mail: marcospiccin@gmail.com, Orcid: http://orcid.org/0000-0002-7254-0036 